INHALT

\title{
Perfektes Rüstzeug
}

Liebe Kolleginnen und Kollegen,

wie ging es Ihnen nach erfolgreich beendetem Zahnmedizinstudium? Einerseits hatte man es endlich geschafft und das Examen in der Tasche, brannte darauf loszulegen. Andererseits stürzte mit dem Berufsleben eine neue Welt über einen ein, in der man dann schnell wieder geerdet wurde.

Bis vor einigen Jahren war der Weg noch klar vorgezeichnet: erst mal zwei Jahre Assistenzzeit und dann Neugründung oder Übernahme einer Praxis, es sei denn, man ging in die Wissenschaft oder in seltenen Fällen in die Industrie. Heute ist der Weg in die Niederlassung für junge Kolleginnen und Kollegen wesentlich komplexer geworden. Und noch immer ist im Studium nichts von Betriebswirtschaft, steuerlichen wie rechtlichen Grundlagen, Psychologie, Mit-

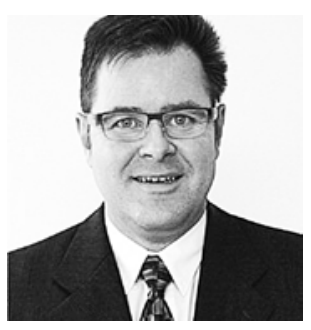

Dirk Ruffing Mitglied im FVDZBundesvorstand arbeiter- und Teamführung, Marketing, geschweige denn einem Sozialgesetzbuch zu hören, das vielleicht das ganze weitere Berufsleben prägt. Und wer hat schon etwas von Freiberuflichkeit gehört? Solchen wichtigen Themen, die an der Universität nicht mal gestreift werden, hat sich der Freie Verband Deutscher Zahnärzte (FVDZ) in Ergänzung seines langjährigen Nachwuchsengagements angenommen und ein Bündel kompakten Wissens geschnürt, wohl dosiert in einem abgestimmten Curriculum. Alle Infos zu dem neuen FVDZ-Existenzgründerprogramm lesen Sie in dieser DFZ-Ausgabe (Seite 16). Ich hätte mir solch ein perfektes Rüstzeug für den Start gewünscht.

Ihr
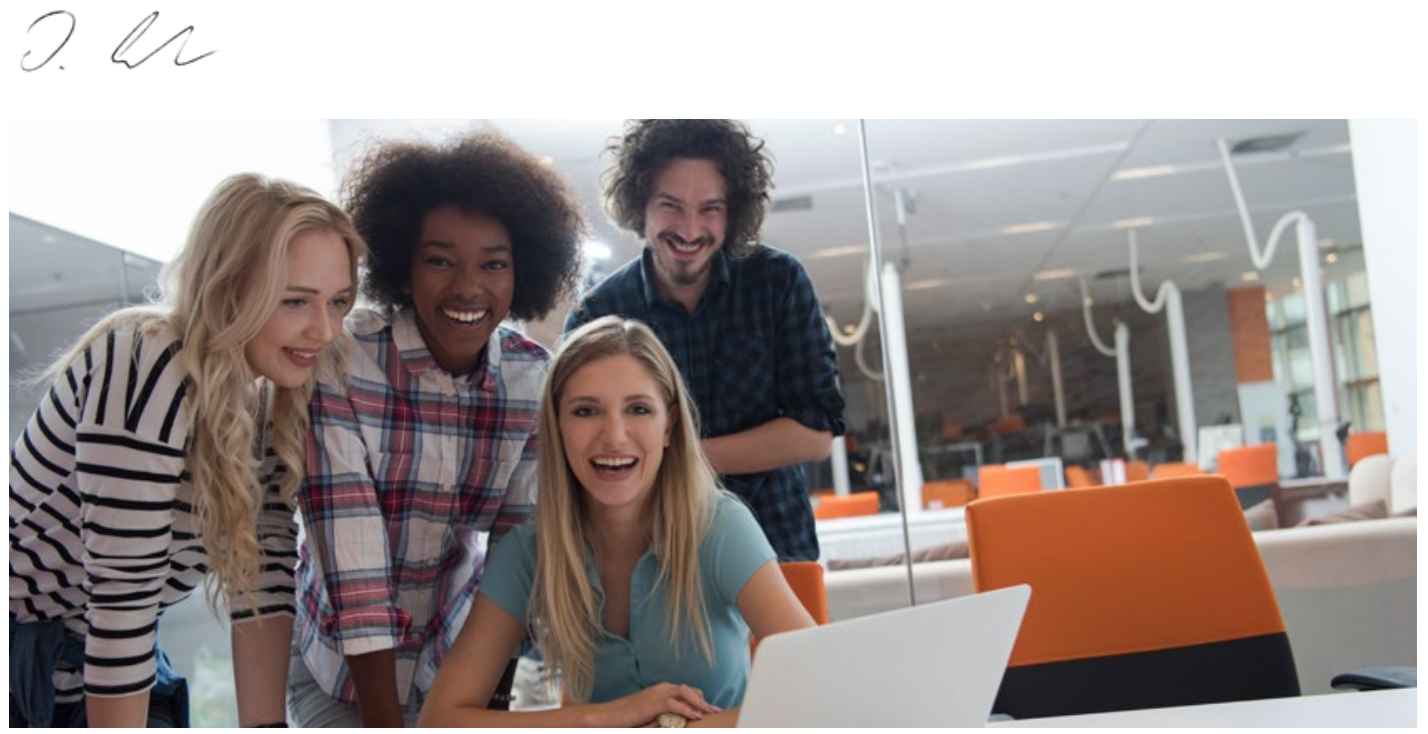